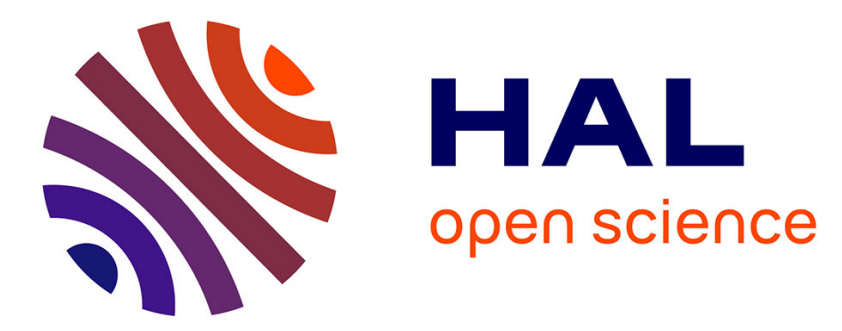

\title{
First Impression Matters: Exploring the Mediating Effect of Previous Experience on the Perception of Beauty and Usability
}

\author{
Suleman Shahid, Omar Mubin
}

\section{- To cite this version:}

Suleman Shahid, Omar Mubin. First Impression Matters: Exploring the Mediating Effect of Previous Experience on the Perception of Beauty and Usability. 15th Human-Computer Interaction (INTERACT), Sep 2015, Bamberg, Germany. pp.555-558, 10.1007/978-3-319-22723-8_60 . hal-01610788

\author{
HAL Id: hal-01610788 \\ https://hal.inria.fr/hal-01610788
}

Submitted on 5 Oct 2017

HAL is a multi-disciplinary open access archive for the deposit and dissemination of scientific research documents, whether they are published or not. The documents may come from teaching and research institutions in France or abroad, or from public or private research centers.
L'archive ouverte pluridisciplinaire HAL, est destinée au dépôt et à la diffusion de documents scientifiques de niveau recherche, publiés ou non, émanant des établissements d'enseignement et de recherche français ou étrangers, des laboratoires publics ou privés.

\section{(c)(1)}

Distributed under a Creative Commons Attribution| 4.0 International License 


\title{
First Impression Matters: Exploring the Mediating Effect of Previous Experience on the Perception of Beauty and Usability
}

\author{
Suleman Shahid ${ }^{1}$ and Omar Mubin ${ }^{2}$ \\ ${ }^{1}$ Tilburg center for Cognition and Communication, \\ Tilburg University, The Netherlands \\ ${ }^{2}$ University of Western Sydney, Australia \\ s.shahid@uvt.nl
}

\begin{abstract}
This study investigated how the previous experience of a product possibly mediates the effect of beauty on usability. In an experiment 32 individuals, half with and half without experience, tested two different, but equally usable espresso machines. The results showed that previous experience had a considerable influence on the effect of beauty on usability.
\end{abstract}

Keywords: Usability, Beauty, Experience

\section{Introduction}

In the past decade the effect of beauty on perceived usability has been thoroughly researched with contradicting results [1]. Recent research on user experience has clearly shown that usability does not stand on its own and is just one attribute in the whole user experience of a product [2]. Hassenzhal's model [3] assumes that a product has certain features that are chosen by a designer to convey a certain intended product 'character'. When users come in contact with a product they first create a personal product character, this is based on their initial expectations and the products functions. On some occasions, users tend to infer attributes, features about their experiences with products. Beauty is an important starting point of the inference processes because it is one of the most immediately available attributes when judging a product [4]. Prior research has shown that that previous experience of the product could possibly mediate the effect of beauty on usability. A study by Hassenzahl \& Monk [5] tried to further examine and clarify the strength and implications of the correlation between beauty and usability. The study however did not show any results of perceived beauty on usability. A suggestion was made that previous experience might be the cause of the lack of correlation between beauty and usability. If a user has no experience with a product, the goodness or usability of a product will be inferred from how beautiful it looks. Therefore the main focus of our research is centered around the question if previous experience mediates the effect of beauty on usability. 


\section{Method}

A total of 32 users participated in this study. 16 participants were active users of automatic espresso machines daily and 16 participants had never used an espresso machine before. All participants were regular coffee drinkers and drank coffee once a day. To measure the previous experience the participants were asked what different ways they had used to make coffee. For choosing one more beautiful and one less beautiful but equally usable machines, we ran two pre-tests. In the pre-test for beauty four espresso machines were presented in an online survey (figure 1), two brand $\mathrm{x}$ (Siemens) espresso machines and two brand y (Saeco) espresso machines. 60 participants participated in the survey where they judged four machines for their beauty, 1 being very beautiful and 7 being very ugly (see figure 1 for results). In order to test the usability of both espresso machines another pre-test was conducted with 10 people who had no previous experience with such espresso machines. We choose two SAECO machines from the same brand because these two machines were significantly different (beautiful vs. ugly) from each other. Furthermore, user interfaces of both machines were exactly the same. By choosing the same brand, we also ensured that taste of the coffee would be the same (because the coffee making process of both machines was same). Each participant had to perform five tasks using both machines (the primary task was to make a coffee). After these tasks they were handed a usability questionnaire (1 for very usable and 7 for unusable), one after each machine and one at the end of the pre-tests. All participants agreed that both machines were equally easy to use and it was mentioned multiple times that the interfaces were 'exactly the same'.
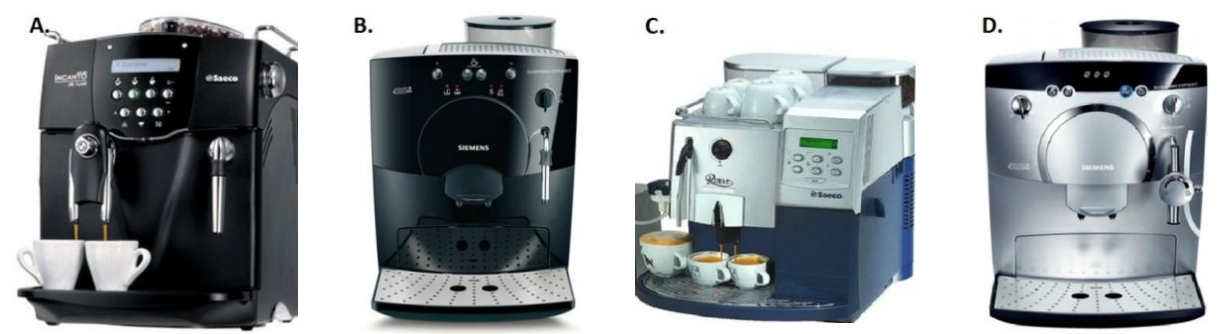

Fig. 1. The coffee machines used in the pre-test $A=$ Saeco Incanto (Avg. beauty: 4.61, Avg. Usability = 2.00) Deluxe, B = Siemens 1 (Avg. beauty =2.75), $\mathrm{C}=$ Saeco Royal Proferssional (Avg. beauty: 3.09, Avg. usability=2.20) and $D=$ Siemens 2 (Avg. beauty: 2.91)

\section{Main Experiment}

The 32 participants were asked to perform five tasks on each espresso machine after which they had to make a cup of coffee and taste it. The participants were divided into four groups, the first group was a group with experience and started with the beautiful espresso machine, the second group was a group with experience and 
started with the less beautiful espresso machine. The third group was a group without previous experience and started with the beautiful espresso machine, the fourth group was again a group without experience and started with the less beautiful espresso machine. The questionnaires were taken from an earlier experiment [5] about the effects of beauty on usability and modified with questions about previous experience with espresso machines. The questionnaires inquired about the taste of the coffee, the previous experience with the espresso machines, the usability of the espresso machines, the beauty of the espresso machines and the willingness to purchase the espresso machines. In order to measure the usability two questions about usability were asked, the first enquired about the ease of use (effectiveness and efficiency) and the second enquired about the satisfaction (pleasing to use). The first and second questionnaire were identical (one for each machine) and were given to the participants after they finished their coffee.

After performing 5 tasks and making a coffee participants were lead back into the main room where they were given time to drink their coffee. Once the participant had drunk the coffee they were asked to fill in questionnaire. They were given a neutralizer, in order to neutralize their taste. The procedure with the first espresso machine was repeated with the second espresso machine. This second machine was placed in a different room than the last espresso machine to make sure they would not see both of them together. While both machines used the same kind of coffee, the participants were asked to rate the coffee they just tasted ( 1 for very tasty and 5 for not tasty at all).

\section{Results}

There was no significant effect of order of the espresso machines for both groups and therefore we combined the results. The results of the t-tests (with Bonferroni correction) show that both the group with previous experience, $\mathrm{t}(15)=9.27, \mathrm{p}<.05$, and the group without previous experience, $\mathrm{t}(15)=8.58, \mathrm{p}<.05$, judged the beautiful espresso machine to be more beautiful than the less beautiful espresso machine. The results of the t-test showed that the group with previous experience did not perceive the usability of both machines to be different from each other, $t(15)=1.95, \mathrm{p}>.05$. However the group without previous experience judged the two machines to be different in usability $t(15)=4.22, \mathrm{p}<.01$. The comparison results show that the group without previous experience judged the beautiful espresso machine also to be the most usable espresso machine, $\mathrm{t}(15)=6.54, \mathrm{p}<.01$. For the group without previous experience there is also a strong positive correlation between the machine they judged to be the most beautiful and the machine they judged to be the most usable $r=.734, n$ $=16, \mathrm{p}<.01$. All results support the claim that previous experience has an effect on the way beauty affects the usability of a machine. Finally the results show that while the group with previous experience judged the taste of the coffee to be the same, $t(15)=$ $.49, \mathrm{p}=.63$, the group without previous experience judged the taste of the coffee made with the more beautiful espresso machine to be better (mean taste of beautiful machine $=1.87$, mean taste of less beautiful machine $=2.62, t(15)=3.50, p<.05$. 


\section{Conclusion and discussion}

The results showed that previous experience mediated and even completely negated the effect beauty has on perceived usability. The group without previous experience judged the beautiful espresso machine to be more usable than the less beautiful espresso machine. The beautiful espresso machine has been found more beautiful than the less beautiful espresso machine by all participants of the experiment. Our results also showed that the group with previous experience did not judge the usability of both machines to be different, while they did judge the beautiful espresso machine to be more beautiful than the less beautiful espresso machine. These findings are in line with previous research $[4,6]$. Our current research supports the claim that beauty has a direct effect on pragmatic quality, at least for individuals without previous experience with the product. This is contrary to prior work [3], where no strong direct correlation between beauty and usability was found. While there is a direct correlation between beauty and usability, a machine, which is perceived to be 'beautiful', is not necessarily usable. The less beautiful espresso machine was also in no way judged to be unusable, it was only judged to be less usable than it's beautiful counterpart. While Hassenzahl \& Monk [4] mention that a brief amount of previous experience is enough to mediate or negate the effect of beauty on usability, this research speculates that a longer 'hands-on' experience is possibly needed before it negates the effect of beauty on usability. The focus of future research could be to control the amount of previous experience of users to make sure variances in experience and expertise do not affect the results obtained.

\section{References}

1. De Angeli, A., Sutcliffe, A., \& Hartmann, J. Interaction, usability and aesthetics: what influences users' preferences? In Proceedings of the 6th ACM Conference on Designing interactive Systems (DIS '06), 271-280 (2006)

2. Hassenzahl, M. The interplay of beauty, goodness and usability in interactive products. Human-computer interaction. Volume 19, 319-349 (2004)

3. Hassenzahl, M. Aesthetics in interactive products: Correlates and consequences of beauty. In H. N. J. Schifferstein \& P. Hekkert (Eds.), Product experience, 287302. (2008)San Diego, CA: Elsevier

4. Hassenzahl, M. \& Monk, A. The Inference of Perceived Usability From Beauty, Human-Computer Interaction, 25:3, 235-260 (2010)

5. Lindgaard, G., Fernandes, G., Dudek, C., \& Brown, J. Attention web designers: You have 50 milliseconds to make a good first impression. Behavior \& Information Technology, 25, 115-126 (2006).

6. Hartmann, J., Sutcliffe, A., \& De Angeli, A. (2007). Investigating attractiveness in web user interfaces.Proceedings of the CHI 07 Conference on Human Factors in Computing Systems. New York: ACM 